\title{
Endoscopic and symptoms analysis in Mexican patients with irritable Bowel syndrome, dyspepsia, and gastroesophageal reflux disease
}

\author{
SANTIAGO CAMACHO, FERNANDO BERNAL, MIGUEL ABDO and RICHARD A. AWAD \\ Experimental Medicine and Motility Unit and Endoscopy Unit, Gastroenterology Service U-107 \\ Mexico City General Hospital, Dr. Balmis \#148, Col. Doctores, 06726 México, D.F., Mexico
}

Manuscript received on May 8, 2009; accepted for publication on August 17, 2010

\begin{abstract}
The aim of this study was to analyze the data of endoscopy and symptoms in 118 Mexican patients with irritable bowel syndrome (IBS), dyspepsia, non-erosive reflux disease (NERD) and erosive esophagitis (EE). IBS criteria were fulfilling for dyspepsia patients in 47\%, for NERD in 48\%, and for EE patients in 48\% of cases. Esophagitis was present in $42 \%$ of patients with IBS and in $45 \%$ of patients with dyspepsia. A higher prevalence of hiatus hernia was found in EE vs. NERD. Heartburn and acid eructation were associated with the presence of esophagitis; acid eructation, regurgitation and nocturnal pain with duodenitis; and heartburn and regurgitation with hiatus hernia. Males more frequently reported: mucus in feces, abdominal distension, nausea and gastritis; and women more frequently reported esophagitis and duodenitis. Patients with NERD (OR 2.54, 95\% CI 1.08 to 5.99, p=0.04), tenesmus and early satiety, and men had an increase risk for reporting hard or lumpy stools. In conclusion, nearly half of the Mexican patients with NERD, EE and dyspepsia fulfill criteria for IBS. A large number of symptoms were correlated with endoscopy, which can be used to improve the indication of the endoscopy and its implementation in clinical studies.
\end{abstract}

Key words: dyspepsia, endoscopy, irritable bowel syndrome, overlap, reflux disease, symptoms.

\section{INTRODUCTION}

The overlap of upper and lower gastrointestinal (GI) symptoms is clearly established in some countries and regions, including Sweden (Bolling-Sternevald et al. 2008), Belgium (Tack et al. 2005), Greece (Papatheodoridis and Karamanolis 2005), France (Guillemot et al. 2005), the United States (Cremonini and Talley 2004, Gasiorowska et al. 2008, Locke et al. 2005), and Asia (Ang et al. 2005). However, the cause of the overlap is not yet clear (Savarino and Savarino 2008). GI symptoms are common in the Japanese population, with an incidence of $25 \%$; abdominal pain, diarrhea, nausea, constipation and dyspepsia are the most frequent symptoms (Tokuda et al. 2007). A recent report revealed a significant trend for an increase in the prevalence of

Correspondence to: Richard Alexander Awad

E-mail: awadrichard@iserve.net.mx gastro-esophageal reflux disease (GERD) symptoms in the general population over time, showing an increase in the prevalence of GERD in the U.S., Singapore and China but not Sweden (El-Serag 2007). Published data show an increased prevalence of irritable bowel syndrome (IBS) in patients with GERD (Pimentel et al. 2002). However, there are few data related with the prevalence of IBS in patients with non-erosive reflux disease (NERD) (Zimmerman and Hershcovici 2008) and erosive esophagitis (EE). In China, a positive association is reported between GERD and IBS (Cheung et al. 2007), and in Turkey an overlap of symptoms of dyspepsia and GERD is reported (Kitapcioglu et al. 2007). Dyspepsia is prevalent worldwide; most of the published studies deals with functional dyspepsia (Geeraerts and Tack 2008), whose prevalence is in the range of $11.5-14.7 \%$; a few refer to organic dyspepsia and 
rarely a study refers to dyspepsia in Hispanic patients (Akhtar and Shaheen 2004). Still, this report of dyspepsia in African-American and Hispanic patients studied Hispanic patients that live outside Latin America (Akhtar and Shaheen 2004). Whether this is true or not for a Mexican population living in Latin America has never been studied, mostly considering that it is not clear if one can refer to Hispanic subjects with the obtained data of Hispanics that live in the United States (Awad 2008). The aim of the current study was to analyze the data of endoscopy and symptoms in Mexican patients with IBS, dyspepsia, NERD and EO.

\section{METHODS}

\section{Patient Population}

The study was conducted in the Experimental Medicine and Motility Unit at the Gastroenterology Service of the Mexico City General Hospital. All procedures were carried out according to Declaration of Helsinki guidelines (including subsequent revisions), and the Ethical and Research Committee of the Mexico City General Hospital approved the protocol. Signed consent was obtained from subjects and treating physicians. One hundred and eighteen patients $(40 \pm 11$ years, 59 women) with upper and lower GI symptoms were consecutively referred during a 15 -month period to our motility-based problems tertiary unit. These patients filled a clinical assessment and questionnaires, underwent upper GI endoscopy, basic laboratory screening (hematocrit, haemoglobin, erythrocytes, leukocytes, creatinine, glucose, three coproparasitoscopic studies, microbiological fecal culture analyses, and wet mount preparation for amoeba), and then entered into a database for further analysis.

\section{DEFINITIONS OF GI DISORDERS}

The patients for this investigation were asked with regard to the presence, duration and severity of symptoms. The latter were scored using a 4-point scale from 0 (no symptom) through 1 (mild: hardly perceived symptoms, only a slight impairment of general well being) and 2 (moderate: clearly noticeable symptoms, but tolerable without immediate relief) to 3 (severe: overwhelming discomfort, urgent desire for immediate relief). We have already used a Spanish language version of this questionnaire in our Mexican population (Awad 1993, Awad et al. 1998, 2006, Awad and Camacho 2002, 2003, Gerson et al. 2008, 2006). After a meticulous evaluation by a gastroenterologist to exclude structural and biochemical abnormalities, patients were diagnosed with IBS according to Rome I criteria (Thompson et al. 1989) if they reported a total of at least three months of abdominal pain or discomfort over the past 12 months with at least one of the following characteristics: the abdominal pain or discomfort was relieved with defecation and it was associated with a change in the frequency or consistency of stool. The diagnosis also required patients to present two or more of the following symptoms for at least three months during the past 12 months: very frequent ( $>$ three times a day) or very rare $(<$ three times a week) stools; changes in stool consistency (liquid, hard, soft or lumpy); difficulty in evacuating stools; urgency or a sensation of incomplete evacuation; presence of bubbles, mucus or white deposits in the stools; and sensations of distension. Dyspepsia was considered if a patient responded affirmatively to the symptom query of pain or discomfort centered in the upper abdomen on the questionnaire, according to the original Rome definition (Talley et al. 1991). In addition, if a structural diagnosis was demonstrated in the upper endoscopy, it was considered as organic dyspepsia. GERD was identified from responses to the questionnaire if a patient reported heartburn at least once a week as a major symptom (Talley et al. 2003) and further classified it as EE or, if they did not have mucosal esophageal changes on upper endoscopy according to the Savary-Miller classification, as non-erosive reflux disease (NERD) (Quigley 2004). Hiatal hernia was diagnosed endoscopically when the distance between the crural impression and the gastroesophageal junction was $2 \mathrm{~cm}$ or more, as stated by other authors (Awad and Camacho 2002, Fein et al. 1999). Endoscopic diagnosis of gastritis and duodenitis was performed according to the Sydney system (Tytgat 1991). The symptoms of acid eructation, nocturnal pain, pain relieved by antacids, nausea, regurgitation, early satiety, abdominal distension, passage of mucus and tenesmus were also recorded. Exclusion criteria included subjects who had previously undergone abdominal or anorectal surgery, had taken any kind of drugs 
during the past month, were pregnant or nursing, or had any concomitant disease. Anonymity was guaranteed, allocating subjects by means of a progressive code.

\section{DATA ANALYSIS AND STATISTICS}

Statistics were calculated using the 2000 GraphPad Software package of statistical programs (San Diego, CA, USA). Averaged data was compared using nonpaired Student $t$-tests, and nonparametric data twotailed Mann-Whitney $U$ tests. Group differences in symptoms were evaluated using Fisher's exact test; associations between symptoms and endoscopy were done with Spearman's correlation. Odds ratios (OR) and 95\% confidence intervals (CI) for OR were calculated. Data throughout the study have been expressed as percentages and mean $\pm \mathrm{SD}$, with an alpha level of 0.05 .

\section{RESULTS}

Of the initial 607 outpatients, 570 were contacted. Of these, 120 patients presenting other GI diseases, as hepatic or anorectal problems, were not included in the present work, 109 refused the endoscopy procedure, and 102 refused to participate due to personal reasons. The remaining 239 patients were scheduled for an interview, but only 125 arrived at the appointment. Of these, seven patients were excluded as they did not fulfill the inclusion criteria. Thus, 118 patients $(40 \pm 11.5$ years, 59 women) were enrolled into the study. According to the definition of GI disorders discussed in Methods, the patients were classified (Fig. 1) as IBS $(\mathrm{n}=52,39 \pm 11$ years, 23 women), dyspepsia $(\mathrm{n}=82,39 \pm$ 10 years, 40 women $)$ and GERD $(n=86,39.5 \pm 11$ years, 45 women). Patients with GERD were further classified as $\mathrm{EE}(\mathrm{n}=41,40.8 \pm 12$ years, 27 women) or NERD $(\mathrm{n}=45,38 \pm 9.8$ years, 18 women). Figure 2 shows that, although present in all groups, abdominal pain and its characteristics pertinent to IBS were more frequent in patients with IBS $(\mathrm{p}<0.05)$. Upper abdominal pain was more frequent in patients with dyspepsia compared with IBS $(p=0.006)$, NERD $(p=0.02)$ and EE $(p=0.01)$. Heartburn was more frequent in NERD and EE compared with IBS $(p=0.02)$ and dyspepsia $(p=0.01)$. Acid eructation was more frequent in EE compared with dyspepsia $(p=0.02)$ and NERD $(p=0.004)$. The recorded symptoms of regurgitation of air, nocturnal pain, pain relieved by antacids, nausea, early satiety, abdominal distension, passage of mucus and tenesmus shown in Figure 3 did not reach statistical significance between groups.

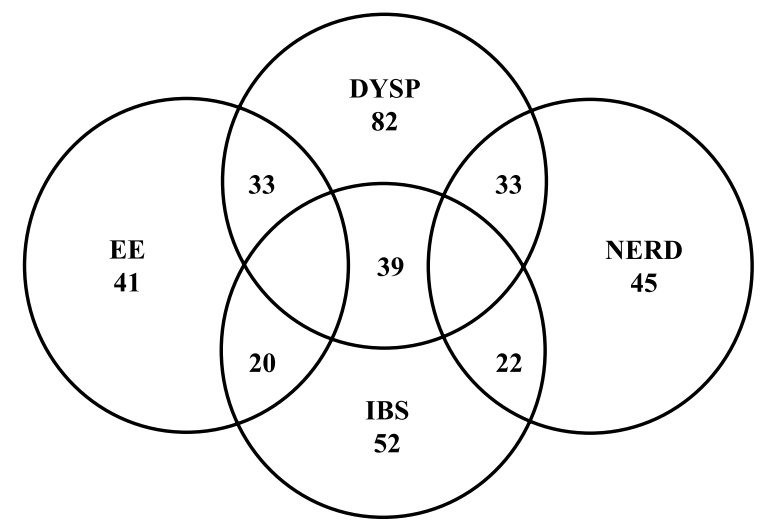

Fig. 1 - Overlap of symptoms among IBS, organic dyspepsia, NERD and $\mathrm{EE}$ in 118 patients.

\section{GENDER}

The female-to-male ratio was 0.79 for IBS, 0.95 for dyspepsia, 0.67 for NERD, and 1.93 for EE. Among the 118 patients, males more frequently than females reported: mucus in feces [27/59 (45\%) vs. 16/59 (27\%), $\mathrm{p}=0.03]$, abdominal distension [58/59 (98\%) vs. 50/59 (84\%), $\mathrm{p}=0.007]$, and nausea $[47 / 59(79 \%)$ vs. 37/59 $(62 \%), p=0.04]$. Gastritis was more frequently present in men [54/59 (91\%) vs. 44/59 (74\%), $\mathrm{p}=0.01]$, and women more frequently reported esophagitis $[32 / 59(54 \%) v s$. $15 / 59(25 \%), \mathrm{p}=0.001]$ and duodenitis [15/59 (25\%) vs. $4 / 59(6 \%), p=0.005]$.

\section{STOOLS}

The frequency of defecation was normal in almost all patients ( $\mathrm{n}=111,12.1 \pm 5$ bowel movements per week); only six patients had less than three bowel movements per week ( $n=6,2 \pm 0$ bowel movements per week), and one patient had 28 bowel movements per week. Among the 118 studied patients, patients with NERD (16/29; OR 2.54, 95\% CI 1.08 to 5.99, $\mathrm{p}=0.04)$, tenesmus $(25 / 29$; OR $6.11,95 \%$ CI 1.96 to $19.00, \mathrm{p}=0.0009$ ), early satiety $(23 / 29$; OR $2.85,95 \%$ CI 1.05 to $7.70, p=0.04)$, and men $(p=0.009)$ had an increase risk for reporting hard or lumpy stools compared with normal defecation. Liquid or soft stools compared with hard or lumpy stools were 


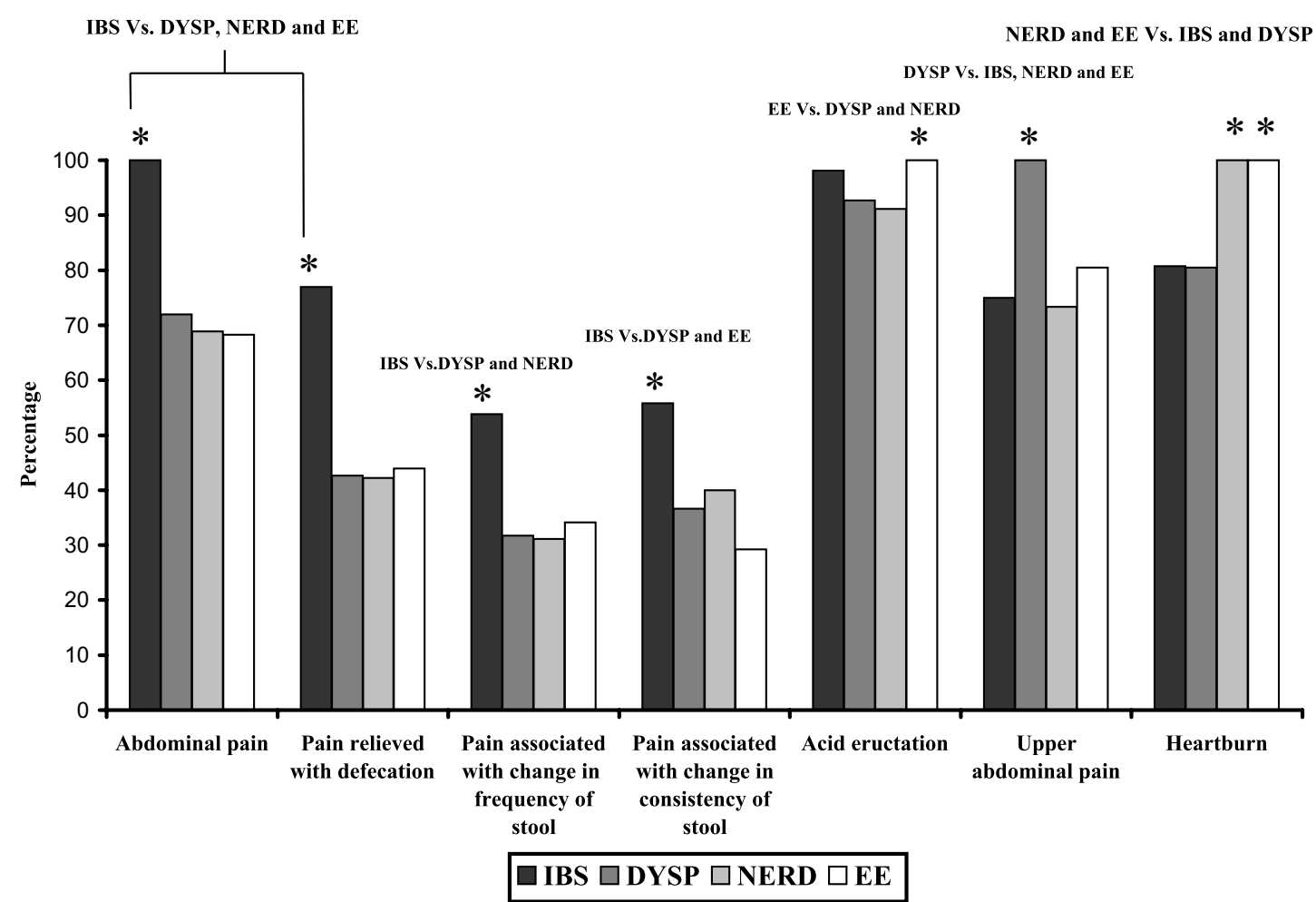

Fig. 2 - The prevalence of statistically significant upper and lower gastrointestinal symptoms in patients with irritable bowel syndrome (IBS), dyspepsia (DYSP), non-erosive reflux disease (NERD) and erosive esophagitis (EE). The figure depicts the percentage of patients having individual symptoms in each group. ${ }^{*}=\mathrm{P}<0.05$.

reported more frequently in patients reporting abdominal pain or discomfort associated with a change in consistency of stools [9/18 (50\%) vs. 6/29 (20\%), $\mathrm{p}=0.03]$.

\section{OVERLAP OF SYMPTOMS}

IBS patients fulfilled criteria for dyspepsia in 39/52 (75\%) of cases, for NERD in 22/52 (42\%), and for EE in $20 / 52(38 \%)$. Dyspepsia patients fulfilled criteria for IBS in 39/82 (47.5\%) of cases, for NERD in 33/82 (40\%), and for EE in 33/82 (40\%). NERD patients fulfilled criteria for IBS in 22/45 (48.8\%) of cases, and for dyspepsia in 33/45 (73\%). EE patients fulfilled criteria for IBS in 20/41 (48.7\%), and for dyspepsia in 33/41 $(80 \%)$.

\section{ENDOSCOPY}

Endoscopy reveals that the most common findings in the 118 patients were gastritis $(98 / 118,83 \%)$, hiatus hernia (97/118, 82\%), esophagitis $(47 / 118,39.8 \%)$ and duodenitis $(19 / 118,16 \%)$. A higher prevalence of hiatus hernia was found in patients with EE (39/41, 95\%) com- pared with NERD patients $(37 / 45,82 \%)$. Hiatus hernia was positively correlated with esophagitis $(r=0.24$, $\mathrm{p}=0.02)$ and gastritis $(\mathrm{r}=0.2, \mathrm{p}=0.02)$. Esophagitis in all patients with EE was also present in 22/52 (42\%) of patients with IBS, and in 37/82 (45\%) of patients with dyspepsia. Hiatus hernia was found in patients with IBS (46/52, 88\%), dyspepsia (71/82, 87.8\%), NERD (37/45, $82 \%)$ and $\mathrm{EE}(39 / 41,95 \%)$ without statistical significance between groups. The same occurs with gastritis in more than $80 \%$ of all groups. The presence of duodenitis was meaningless as it was in the rank of $11-24 \%$. A number of symptoms correlated statistically with endoscopy. Heartburn $(r=0.20, p=0.02)$ and acid eructation $(\mathrm{r}=0.27, \mathrm{p}=0.003)$ were associated with the presence of esophagitis. Heartburn $(r=0.25, p=0.005)$ and regurgitation of air $(r=0.22, p=0.01)$ were associated with the presence of hiatus hernia. Acid eructation $(\mathrm{r}=0.22$, $\mathrm{p}=0.014)$, regurgitation of air $(\mathrm{r}=0.18, \mathrm{p}=0.04)$ and nocturnal pain $(\mathrm{r}=0.28, \mathrm{p}=0.002)$ were associated with the presence of duodenitis. Regurgitation of air was also associated with gastritis $(r=0.21, p=0.02)$. All of our 


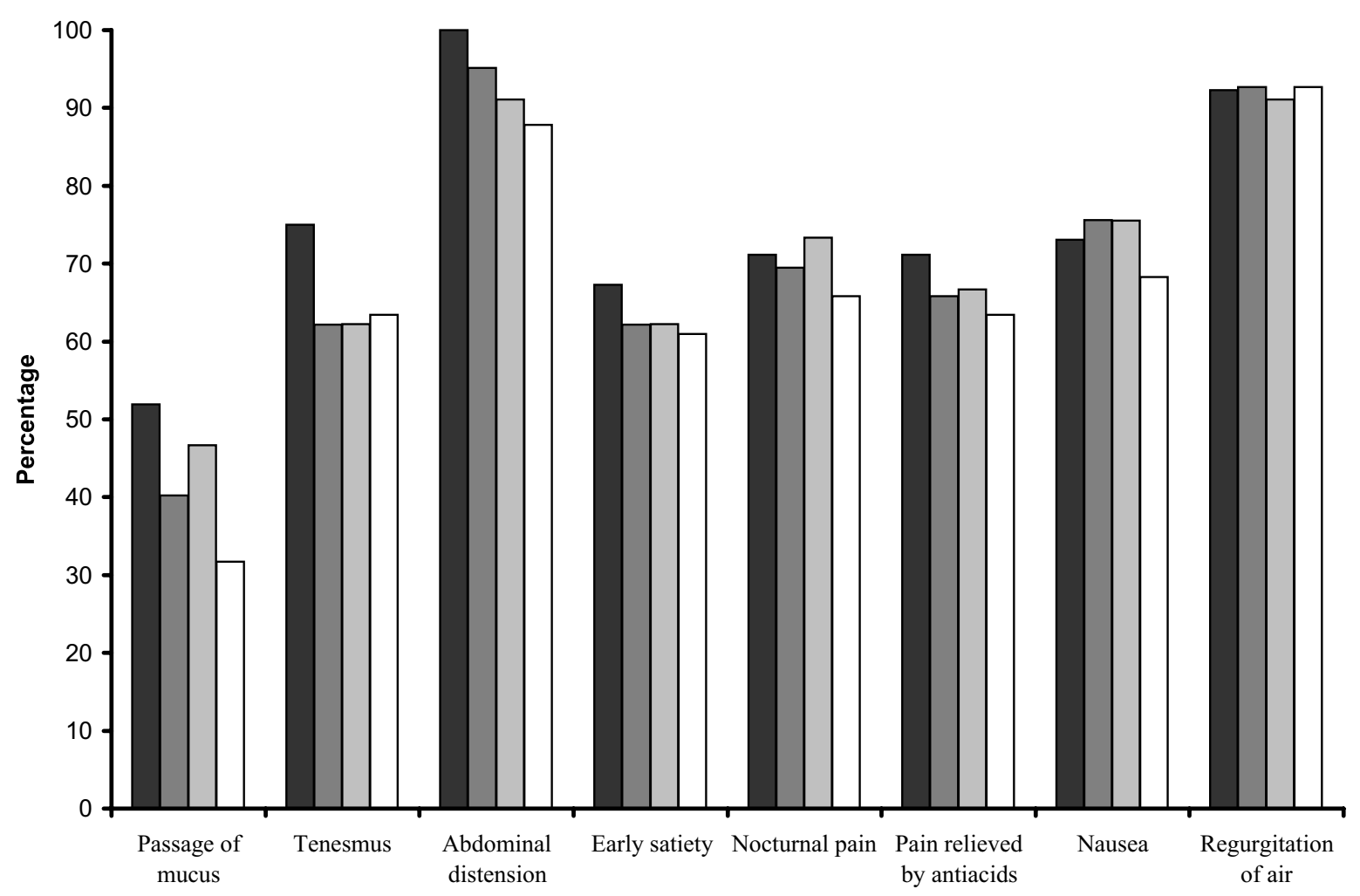

$\square$ IBS $\square$ DYSP $\square$ NERD $\square E E$

Fig. 3 - Upper and lower GI symptoms shared by 118 patients with irritable bowel syndrome (IBS), dyspepsia (DYSP), non-erosive reflux disease (NERD) and erosive esophagitis (EE), but without statistical significance. The figure depicts the percentage of patients having individual symptoms in each group.

patients with dyspepsia presented alteration at the endoscopy. Esophagitis was present in 7/82 (8.54\%), gastritis in 40/82 (48.78\%), esophagitis and gastritis in 22/82 (26.83\%), gastritis and duodenitis in 5/82 (6.1\%) and; esophagitis, gastritis and duodenitis in 8/82 (9.76\%).

\section{DISCUSSION}

Symptom assessment using questionnaires has been recommended as the primary outcome measure in clinical GERD and dyspepsia trials (Fraser et al. 2005). Questionnaires have to assess the frequency and severity (Stanghellini et al. 2004) of GERD or dyspepsia symptoms in a sample of patients. However, although a number of measures have been developed, it remains unclear which ones should be used in new trials due to methodological heterogeneity (Stanghellini et al. 2004). In addition, a comprehensive review concluded that no adequate scale currently exists for the evaluation of changes in GERD symptoms (Armstrong et al. 2004). Therefore, further research is necessary to compare existing outcome measures to determine which are the most reliable, valid and responsive instruments (Fraser et al. 2005). In our research unit, we have been using an inventory that comprises items chosen from previously published literature and the Rome I criteria (Talley et al. 1991, 2003, Thompson et al. 1989).

Bloating, belching, regurgitation of air, heartburn, upper abdominal pain, nausea and early satiety were the most frequently reported upper GI symptoms in our Hispanic patients with IBS. This information agrees with another work previously published (Talley et al. 2003). Early satiety was present in about $60 \%$ of patients with IBS, subtypes of GERD and dyspepsia. For this reason we do not fully agree with the concept that a major gastroduodenal motor disorder should be suspected if there is severe early satiation (Talley 2007). 
Upper GI symptoms traditionally associated to dyspepsia and GERD were present in our Mexican patients who were classified as having IBS, among whom $75 \%$ had dyspepsia, $42 \%$ NERD and $38 \%$ EE. These data agree with a recent review reporting that, in at least $40 \%$ of the patients presented to a gastroenterologist, functional dyspepsia and IBS overlap considerably (Cremonini and Talley 2004), and mostly agree with a Swedish study in which the overlap reached $87 \%$ of subjects reporting abdominal symptoms (Agreus et al. 1995). Upper GI symptoms consistent with dyspepsia were equally frequent in IBS and GERD. Related to this, Talley et al. reported that upper GI symptoms consistent with functional dyspepsia were more frequent in IBS-C compared with IBS-D (Talley et al. 2003). In our study, $80 \%$ of the EE and $73 \%$ of the NERD patients met the diagnosis of dyspepsia. Linked to this matter, heartburn is considered a primary symptom highly specific to GERD. However, we also found a positive association between dyspepsia and heartburn (Fisher exact test $\mathrm{p}=0.007$ ). This is consistent with a report which states that Japanese patients with GERD suffer not only from reflux symptoms, but also from acid-related dyspepsia (Kusano et al. 2007).

Other investigators have stated that the relevance of gender in terms of symptom expression in IBS is uncertain and likely to be minor (Talley et al. 2003). However, we observed some differences. Among the 118 subjects, males reported much more frequently mucus in feces, abdominal distension, nausea and gastritis, while esophagitis and duodenitis were more prevalent in women. In contrast to NERD, females predominated in EE, which is against a report made by a Swedish, group (Agreus et al. 1995). Another observation in our study was that the age of patients with NERD was not significant compared with EE patients, which differs from a report coming from a multiethnic Asian country. At this country they found that patients with NERD were younger than the ones with EE (Ang et al. 2005). It also differs from a German report in 190 patients that found that patients with NERD are older than those with EE (Gockel et al. 2007).

In the present study, stool consistency correlated both with upper and lower GI symptoms, which suggest that the change of stool consistency should be taken into account when performing inquiries in all GI system disorders. More to the point, patients with NERD, tenesmus, early satiety and men had an increase risk for reporting hard or lumpy stools. Furthermore, liquid stools were more frequently reported in patients with abdominal pain or discomfort associated with a change in the consistency of stool. These data agree with a study in children with recurrent abdominal pain for which the presence of watery stool was positively related to pain (Shulman et al. 2007). Regarding IBS, our patients mainly fell into the group of those with alternating bowel habits. Our experience in Latin America does not fully agree with the percentages reported abroad, as the IBS corresponding to the alternating group is noteworthy in our Hispanic population (Awad 1993, Awad et al. 1995, 1998, 2000, Awad and Quilici 2005, Gerson et al. 2008, 2006). Our data agree with a recent report from the United States where most of the patients with IBS reports alternating constipation and diarrhea (Hungin et al. 2005).

The overlapping of upper and lower GI symptoms in IBS, dyspepsia, NERD and EE in our Mexican patients is evident and significant. In the present study, dyspepsia and GERD were more frequently reported than IBS symptoms, which is the same reported on a Greek urban general population (Papatheodoridis and Karamanolis 2005). In the present study, half of the NERD, EE and dyspepsia patients met the diagnosis of IBS as defined by the Rome I criteria. Pimentel et al. (Pimentel et al. 2002) have reported a higher prevalence of IBS in subjects with GERD compared with subjects without GERD. However, our data in Hispanic subjects showed similar prevalence of IBS in patients with NERD, EE and dyspepsia. Different methodology for the selection of patients may account for this difference, as well as for the fact that Pimentel et al. (Pimentel et al. 2002) selected subjects with GERD and we separate GERD in NERD and EE patients. Our NERD patients fulfilled criteria for IBS in $48.8 \%$ of cases, similar to the $49 \%$ reported by Zimmerman et al. (Zimmerman and Hershcovici 2008).

Heartburn $(\mathrm{r}=0.20, \mathrm{p}=0.02)$ and acid eructation $(\mathrm{r}=0.27, \mathrm{p}=0.003)$ were associated with the presence of esophagitis. Forty-two percent of our IBS patients had endoscopic esophagitis, showing that patients with IBS may have more frequent endoscopy change in the up- 
per GI system than we actually think; adding the fact of the overlapping of upper GI symptoms, the use of acid blockers in IBS is supported if the patient has GERD symptoms. It is reported that hiatus hernia is related to the pathogenesis of reflux disease, correlates with more severe endoscopy findings, and predisposes for severe histological abnormality in cases of NERD (Gatopoulou et al. 2005). We agree, as hiatus hernia was present in almost $90 \%$ of our patients with IBS, dyspepsia, NERD and EE. Heartburn $(r=0.25, \mathrm{p}=0.005)$ and regurgitation of air $(r=0.22, p=0.01)$ were associated with the presence of hiatus hernia, which agree with a report from Iran and the Middle East which states that hiatus hernia is associated with reflux esophagitis (Rezailashkajani et al. 2007), a report from Prague in which reflux esophagitis is present in $50 \%$ of patients with hiatal hernia (Tenaiova et al. 2007), and a report from Italy in which hiatus hernia was associated with frequent reflux symptoms and esophagitis (Zagari et al. 2008). As reported (Fass 2007), we found a higher prevalence of hiatus hernia in patients with EE compared with NERD patients.

A limitation of this study could be a referral bias, which is always possible in clinical studies (Loftus and Sandborn 2001). However, we identified our patients through their care by primary care physicians, not by gastroenterologists. This happened because, although our research unit is a tertiary care centre, the patients arrive first at the external consultation of the Mexico City General Hospital, which attends patients from all social classes and regions of Mexico. From there, the patients are referred to our unit. In addition, previous publications have identified the population from which we gathered our patients as representative of the general Mexico population (Awad 1993, 2005, Awad et al. 1995, 1998, 2000, 2006, Awad and Camacho 2002, 2003, Gerson et al. 2008, 2006). Another limitation in this work could be that we do not use Rome III criteria. In fact, there is a lot of controversy regarding this issue. Recently Whitehead et al. (Whitehead and Drossman 2010), reviewing the evidence for validity of symptombased criteria (Manning, Rome I, Rome II, and Rome III) for IBS, concludes that there are no consistent differences in sensitivity or specificity between Rome I and Rome II. However, Rome III tests are needed. Other researchers agree with this notion in the context that Rome I criteria are more sensitive than Rome II ones for the diagnosis of IBS, that Rome I is more sensitive than Rome II in female IBS patients; and that there is substantial agreement between Rome I and Rome II criteria for IBS (Saito et al. 2003, Thompson et al. 2002). Rome II criteria do not seem to identify a different group of functional GI disorder sufferers compared with the earlier Rome I criteria (Boyce et al. 2006) and is remarkably insensitive, and if rigidly applied in the clinical situation would lead to much diagnostic uncertainty (Lea et al. 2004). For Rome III, it is reported that patients identified by Rome III criteria for functional constipation and IBS-C are not distinct groups. Finally, it is reported that Rome II and Rome III IBS subtypes are in high agreement and behave similarly over time. Therefore, studies that will use Rome II subtype criteria and studies that will use Rome III criteria will define comparable populations.

In conclusion, about half of the patients with NERD, EE and dyspepsia fulfills the Rome criteria for IBS. A large number of symptoms correlated with endoscopy can be used to improve the indication of the endoscopy and its implementation in clinical studies.

\section{RESUMO}

O objetivo deste estudo foi analisar os dados de endoscopia e sintomas de 118 pacientes mexicanos com síndrome do intestino irritável (IBS), dispepsia, doença do refluxo não-erosiva (NERD) e esofagite erosiva (EE). Os pacientes com IBS preencheram os critérios para dispepsia em 47\%, para NERD em $48 \%$, e para pacientes EE em $48 \%$ dos casos. Esofagite estava presente em $42 \%$ dos pacientes com IBS e em $45 \%$ dos pacientes com dispepsia. A maior prevalência de hérnia de hiato foi encontrada na EE em comparação com NERD. Azia e eructação ácida foram associadas à presença de esofagite; eructação ácida, regurgitação e dor noturna, com duodenite; e azia e regurgitação com hérnia de hiato. Os homens relataram mais frequentemente sintomas como muco nas fezes, distensão abdominal, náuseas e gastrite, enquanto que as mulheres mais frequentemente relataram esofagite e duodenite. Os pacientes com NERD (OR 2,54, IC 95\% 1,08-5,99, p = $0,04)$, apresentaram tenesmo e saciedade precoce, e os homens tiveram um risco aumentado relacionado a fezes endurecidas ou fragmentadas. Em conclusão, quase metade dos pacientes mexicanos com NERD, EE e dispepsia preenchem os critérios 
para a IBS. Um grande número de sintomas foi correlacionado com a endoscopia, esta correlação pode ser utilizada para aumentar a indicação da endoscopia e sua aplicação em estudos clínicos.

Palavras-chave: dispepsia, endoscopia, síndrome do intestino irritável, sobreposição, doença do refluxo, sintomas.

\section{REFERENCES}

Agreus L, Svardsudd K, Nyren O And Tibblin G. 1995. Irritable bowel syndrome and dyspepsia in the general population: overlap and lack of stability over time. Gastroenterology 109: 671-680.

Akhtar AJ And Shaheen MA. 2004. Dyspepsia in African-American and Hispanic patients. J Natl Med Assoc 96: 635-640.

ANG TL, Fock KM, NG TM, TEO EK, CHUA TS AND TAN J. 2005. A comparison of the clinical, demographic and psychiatric profiles among patients with erosive and non-erosive reflux disease in a multi-ethnic Asian country. World J Gastroenterol 11: 3558-3561.

Armstrong D, Monnikes H, Bardhan KD and StanGHELLINI V. 2004. The construction of a new evaluative GERD questionnaire - methods and state of the art. Digestion 70: 71-78.

AWAD RA. 1993. Altered recto-anal motility in irritable bowel syndrome: a clinical physiological study of 80 Mexican patients. J Gastrointest Motil (currently Neurogastroenterol Motil) 5: 265-271.

AWAD RA. 2005. Biofeedback treatment of fecal incontinence incorporating a mental variable without instrumentation: a prospective pilot study in Hispanic population. Acta Gastroenterol Latinoam 35: 230-237.

AWAD RA. 2008. Is it correct to refer to Hispanic subjects with obtained data of Hispanics that live in the United States? J Clin Gastroenterol 42: 1119.

AWAD RA AND CAMACHO S. 2002. Helicobacter pylori infection and hiatal hernia do not affect acid reflux and esophageal motility in patients with gastro-esophageal reflux. J Gastroenterol 37: 247-254.

AWAD RA AND CAMACHO S. 2003. Reference values for stationary and 24-hour ambulatory esophageal manometry and $\mathrm{pH}$ data in Hispanic population. Arch Med Res 34: 388-393.

AwAD RA AND QUilici FA. 2005. Síndrome de Intestino Irritable. Factores poco conocidos. In: ZAPATA C (Ed), Avances en la Gastroenterología en las Américas. Lima, Perú: Asociación Interamericana de Gastroententerología, p. 113-120.
AWAd R, DibILdox M AND ORTIZ F. 1995. Irritable bowel syndrome treatment using pinaverium bromide as a calcium channel blocker. A randomized double-blind placebo-controlled trial. Acta Gastroenterol Latinoam 25: $137-144$.

AWAD RA ET AL. 1998. Transrectal ultrasonography: relationship with anorectal manometry, electromyography and sensitivity tests in irritable bowel syndrome. Int $\mathbf{J}$ Colorectal Dis 13: 82-87.

Awad RA, Llorens F, CAmelo AL And SAnchez M. 2000. A randomised double-blind placebo-controlled trial of lidamidine HCL in irritable bowel syndrome. Acta Gastroenterol Latinoam 30: 169-175.

Awad RA, Camacho S, Martin J And Rios N. 2006. Rectal Sensation, Pelvic Floor Function, and Symptom Severity in Hispanic Population with Irritable Bowel Syndrome with Constipation. Colorectal Dis 8: 488-493.

Bolling-Sternevald E, Aro P, Ronkainen J, StorsKRUBb T, TAlley NJ, Junghard O AND Agreus L. 2008. Do gastrointestinal symptoms fluctuate in the short-term perspective? The Kalixanda study. Dig Dis 26: 256-263.

Boyce PM, Talley NJ, Burke C and Koloski NA. 2006. Epidemiology of the functional gastrointestinal disorders diagnosed according to Rome II criteria: an Australian population-based study. Intern Med J 36: 28-36.

Cheung TK, LAM KF, Hu WHC, LAM CLK, Wong WM, Hui WM, Lai KC, AM SK AND WONG BCY. 2007. Positive association between gastro-oesophageal reflux disease and irritable bowel syndrome in a Chinese population. Aliment Pharm Therap 25: 1099-1104.

Cremonini F And Talley NJ. 2004. Review article: the overlap between functional dyspepsia and irritable bowel syndrome - a tale of one or two disorders? Aliment Pharmacol Ther 20 (Suppl 7): 40-49.

EL-SERAG HB. 2007. Time trends of gastroesophageal reflux disease: a systematic review. Clin Gastroenterol Hepatol 5: 17-26.

FASS R. 2007. Erosive esophagitis and nonerosive reflux disease (NERD): comparison of epidemiologic, physiologic, and therapeutic characteristics. J Clin Gastroenterol 41: 131-137.

Fein M, Ritter MP, Demeester Tr, Oberg S, Peters JH, Hagen JA And BREMner CG. 1999. Role of the lower esophageal sphincter and hiatal hernia in the pathogenesis of gastroesophageal reflux disease. J Gastrointest Surg 3: 405-410.

Fraser A, Delaney B and Moayyedi P. 2005. Symptom-based outcome measures for dyspepsia and GERD trials: a systematic review. Am J Gastroenterol 100: $442-452$. 
GASIOROWSKA A, POH CH AND FAss R. 2008. Gastroesophageal Reflux Disease (GERD) and Irritable Bowel Syndrome (IBS) - Is It One Disease or an Overlap of Two Disorders? Dig Dis Sci 54: 1829-1834.

Gatopoulou A, Mimidis K, Giatromanolaki A, Papadopoulos V, Polychronidis A, Lyratzopoulos N, Sivridis E AND Minopoulos G. 2005. Impact of hiatal hernia on histological pattern of nonerosive reflux disease. BMC Gastroenterol 5: 2.

Geeraerts B And TACK J. 2008. Functional dyspepsia: past, present, and future. J Gastroenterol 43: 251-255.

Gerson MJ, Gerson CD, AWAD RA, DANCEY C, Poitras P, Porcelli P And Sperber AD. 2006. An international study of irritable bowel syndrome: Family relationships and mind-body attributions. Soc Sci Med 62: $2838-2847$.

Gerson CD, Gerson MJ, Awad RA, Chowdhury A, Dancey C, Poitras P, Porcelli P, Sperber A AND WANG WA. 2008. Irritable bowel syndrome: an international study of symptoms in eight countries. Eur J Gastroenterol Hepatol 20: 659-667.

Gockel I, Heintz A, Domeyer M, Kneist W, Trinh TT AND JUNGINGER T. 2007. [Nonerosive and erosive gastroesophageal reflux disease. Long-term results of laparoscopic anterior semifundoplication]. Chirurg 78: $35-39$.

Guillemot F, Ducrotte P And Bueno L. 2005. Prevalence of functional gastrointestinal disorders in a population of subjects consulting for gastroesophageal reflux disease in general practice. Gastroenterol Clin Biol 29: 243-246.

Hungin AP, Chang L, Locke GR, Dennis EH AND BARGHOUT V. 2005. Irritable bowel syndrome in the United States: prevalence, symptom patterns and impact. Aliment Pharmacol Ther 21: 1365-1375.

Kitapcioglu G, Mandiracioglu A, Bor CC And Bor S. 2007. Overlap of symptoms of dyspepsia and gastroesophageal reflux in the community. Turk J Gastroenterol 18: 14-19.

Kusano M ET AL. 2007. Proton pump inhibitors improve acid-related dyspepsia in gastroesophageal reflux disease patients. Dig Dis Sci 52: 1673-1677.

Lea R, Hopkins V, Hastleton J, Houghton LA And WhORWELl PJ. 2004. Diagnostic criteria for irritable bowel syndrome: utility and applicability in clinical practice. Digestion 70: 210-213.

Locke GR III, Zinsmeister AR, Fett SL, Melton LJ III AND TALLEY NJ. 2005. Overlap of gastrointestinal symptom complexes in a US community. Neurogastroenterol Motil 17: 29-34.
LOFTUS EV JR AND SANDBORN WJ. 2001. Lymphoma risk in inflammatory bowel disease: influences of referral bias and therapy. Gastroenterology 121: 1239-1242.

PAPATHEODORIDIS GV AND KARAMANOLIS DG. 2005. Prevalence and impact of upper and lower gastrointestinal symptoms in the Greek urban general population. Scand J Gastroenterol 40: 412-421.

Pimentel M, Rossi F, Chow EJ, Ofman J And FulLERTON S. 2002. Increased prevalence of irritable bowel syndrome in patients with gastroesophageal reflux. J Clin Gastroenterol 34: 221-224.

QUigLEY EM. 2004. Functional dyspepsia (FD) and nonerosive reflux disease (NERD): overlapping or discrete entities? Best Pract Res Clin Gastroenterol 18: 695-706.

Rezailashkajani M, Roshandel D, Shafaee S AND ZALI MR. 2007. High prevalence of reflux oesophagitis among upper endoscopies of Iranian patients. Eur $\mathrm{J}$ Gastroenterol Hepatol 19: 499-506.

Saito YA, Talley NJ, Melton J, Fett S, Zinsmeister AR AND LOCKE GR. 2003. The effect of new diagnostic criteria for irritable bowel syndrome on community prevalence estimates. Neurogastroenterol Motil 15: 687694.

SAVARINO V AND SAVARINO E. 2008. Is acid relevant in the genesis of dyspeptic symptoms associated with nonerosive reflux disease? Eur J Gastroenterol Hepatol 20: 252254.

Shulman RJ, EAKIN MN, JARRETT M, CZYZEWSKi DI AND ZELTZER LK. 2007. Characteristics of pain and stooling in children with recurrent abdominal pain. J Pediatr Gastroenterol Nutr 44: 203-208.

Stanghellini V, Armstrong D, Monnikes H AND BARDHAN KD. 2004. Systematic review: do we need a new gastro-oesophageal reflux disease questionnaire? Aliment Pharmacol Ther 19: 463-479.

TACK J, CAenepeel P, ARts J, LeE KJ, Sifrim D AND JANSSENS J. 2005. Prevalence and symptomatic impact of non-erosive reflux disease in functional dyspepsia. Gut 54: $1370-1376$.

TALLEY NJ. 2007. How to manage the difficult-to-treat dyspeptic patient. Nat Clin Pract Gastroenterol Hepatol 4: $35-42$.

Talley NJ, Colin-Jones D, Koch KL, Koch M, Nyren O And Stanghellini V. 1991. Functional dyspepsia: a classification with guidelines for diagnosis and manegement. Gastronterol Int 4: 145-160.

Talley NJ, Dennis EH, Schettler-Duncan VA, Lacy BE, Olden KW AND Crowell MD. 2003. Overlapping upper and lower gastrointestinal symptoms in irritable bowel syndrome patients with constipation or diarrhea. Am J Gastroenterol 98: 2454-2459. 
TENAIOVA J ET AL. 2007. [Incidence of hiatal hernias in the current endoscopic praxis]. Cas Lek Cesk 146: 74-76.

Thompson WG, Dotevall G, Drossman DA, Heaton KW AND KRUIS W. 1989. Irritable bowel syndrome: guidelines for the diagnosis. Gastronterol Int 2: 92-95.

Thompson WG, Irvine EJ, Pare P, Ferrazzi S And RANCE L. 2002. Functional gastrointestinal disorders in Canada: first population-based survey using Rome II criteria with suggestions for improving the questionnaire. Dig Dis Sci 47: 225-235.

Tokuda Y, Takahashi O, Ohde S, Shakudo M, Yanai H, Shimbo T, Fukuhara S, Hinohara S AND FUKUI T. 2007. Gastrointestinal symptoms in a Japanese population: a health diary study. World J Gastroenterol 13: $572-578$.
Tytgat GN. 1991. The Sydney System: endoscopic division. Endoscopic appearances in gastritis/duodenitis. J Gastroenterol Hepatol 6: 223-234.

WhiteheAd WE AND Drossman DA. 2010. Validation of symptom-based diagnostic criteria for irritable bowel syndrome: a critical review. Am J Gastroenterol 105: 814-820.

ZAGARI RM ET AL. 2008. Gastro-oesophageal reflux symptoms, oesophagitis and Barrett's oesophagus in the general population: the Loiano-Monghidoro study. Gut 57: 1354-1359.

Zimmerman J AND HershCOVICI T. 2008. Bowel symptoms in nonerosive gastroesophageal reflux disease: nature, prevalence, and relation to acid reflux. J Clin Gastroenterol 42: 261-265. 